\title{
Neurostimulatory and ablative treatment options in major depressive disorder: a systematic review
}

\author{
Pablo Andrade • Lieke H. M. Noblesse • Yasin Temel • \\ Linda Ackermans • Lee W. Lim • \\ Harry W. M. Steinbusch • Veerle Visser-Vandewalle
}

Received: 18 December 2009 / Accepted: 22 December 2009 / Published online: 26 January 2010

(C) The Author(s) 2010. This article is published with open access at Springerlink.com

\begin{abstract}
Introduction Major depressive disorder is one of the most disabling and common diagnoses amongst psychiatric disorders, with a current worldwide prevalence of $5-10 \%$ of the general population and up to $20-25 \%$ for the lifetime period.

Historical perspective Nowadays, conventional treatment includes psychotherapy and pharmacotherapy; however, more than $60 \%$ of the treated patients respond unsatisfactorily, and almost one fifth becomes refractory to these therapies at long-term follow-up.
\end{abstract}

P. Andrade $(\bowtie) \cdot$ Y. Temel $\cdot$ L. W. Lim $\cdot$ H. W. M. Steinbusch Department of Neuroscience, Faculty of Health,

Medicine and Life Sciences, Maastricht University,

Universiteitssingel 50, Box 38, 6200 MD Maastricht,

The Netherlands

e-mail: p.andrade@np.unimaas.nl

P. Andrade L. H. M. Noblesse $\cdot$ Y. Temel $\cdot$ L. Ackermans $\cdot$

L. W. Lim $\cdot$ V. Visser-Vandewalle

Department of Neurosurgery,

Maastricht University Medical Center,

Maastricht, The Netherlands

P. Andrade - Y. Temel - L. W. Lim • H. W. M. Steinbusch •

V. Visser-Vandewalle

European Graduate School of Neuroscience (EURON),

Maastricht, The Netherlands

L. H. M. Noblesse $\cdot$ Y. Temel $\cdot$ L. Ackermans •

V. Visser-Vandewalle

Maastricht Institute of Neuromodulative Development (MIND),

Maastricht, The Netherlands

L. H. M. Noblesse

Department of Psychiatry and Neuropsychology,

Maastricht University Medical Center,

Maastricht, The Netherlands
Nonpharmacological techniques Growing social incapacity and economic burdens make the medical community strive for better therapies, with fewer complications. Various nonpharmacological techniques like electroconvulsive therapy, vagus nerve stimulation, transcranial magnetic stimulation, lesion surgery, and deep brain stimulation have been developed for this purpose.

Discussion We reviewed the literature from the beginning of the twentieth century until July 2009 and described the early clinical effects and main reported complications of these methods.

Keywords Major depressive disorder - Electroconvulsive therapy - Vagus nerve stimulation - Transcranial magnetic stimulation · Psychosurgery · Deep brain stimulation

\section{Introduction}

Major depressive disorder (MDD) is one of the most disabling and common diagnoses throughout psychiatric disorders. It represents a current prevalence of 5\% to $10 \%$ of the general population according to worldwide largescale studies, and up to $20 \%$ to $25 \%$ for the lifetime period [98, 122]. Conventional treatment includes psychotherapy and a wide number of antidepressant drugs; however, over $60 \%$ of treated patients responds unsatisfactorily, and almost one fifth becomes refractory to these treatments at long-term follow-up [1, 31, 69, 86, 91]. Therapy failure can lead to a life-threatening situation illustrated by the high number of suicides occurring in up to $15 \%$ of individuals [1]. In an attempt to find solutions for this intractable disorder, other more invasive methods have been developed. 
Search strategy

All articles and textbooks containing nonpharmacological treatments for MDD, with the exception of psychotherapeutic therapies, were reviewed. The reports were found via Medline search (PubMed) using the following keywords and their combinations: MDD, depression, electroconvulsive therapy (ECT), vagus nerve stimulation (VNS), transcranial magnetic stimulation (TMS), psychosurgery, and deep brain stimulation (DBS). In total, 252 reports and eight textbooks were found describing the use of nondrugrelated and nonpsychotherapeutic treatments for depression. Finally, 109 reports were selected for this review; the rest of the articles were excluded due to data repetition or absence of clinical outcome information.

Ablative surgery included lobotomy/leucotomy, orbital and cortical undercutting, cingulectomy (cingulotomy), subcaudate tractotomy, and limbic leucotomy (subcaudate tractotomy with anterior cingulotomy) $[17,18,55,62,78$, 104, 120]. Targets for DBS included the subgenual cingulate cortex (Brodmann area 25), nucleus accumbens, ventral caudate/striatum, inferior thalamic peduncle, globus pallidus internus, and the lateral habenula $[5,51,64,72,73$, $100,101]$. In this review, we present the early clinical outcome and complications of these different methods.

\section{Historical perspective}

Depression is a nosologic entity that has afflicted humankind throughout its existence. The first description of a depressive state was made at the era of Hellenic enlightenment by Hippocrates, derived from one of the four humors, the melancholia. In ancient times, brain surgery was performed to treat mental problems in order to exorcise or appease spirits and ghosts. In 1888, the psychiatrist Gottlieb Burkhardt performed one of the first psychosurgical interventions through cortical excisions with the intention to treat a diagnosed mental illness, schizophrenia in that case. Even though the majority of his patients improved, one of them died, and many others presented serious complications due to the procedure [110]. Consequently, his results were interpreted as careless and unreliable, leaving place to almost 50 years without any related attempt to treat the medically refractory cases. It was not until 1936 that António Egas Moniz, in collaboration with Almeida Lima, brought in modern psychosurgery with apparent better results; these contributions to science led Moniz to receive the Nobel Prize in 1949 [78]. Together, they developed the technique of prefrontal leucotomy to treat severe mental disorders, based on previous studies in primates performed by Fulton and Jacobsen, where frontal lobes were completely removed in two chimpanzees [39]. A few years later, Walter Freeman and James Watts performed lobotomies on numerous cases and popularized this procedure. They even introduced a novel orbital approach with the use of the so-called ice-pick leucotome [37, 38, 118]. Until the 1950 s, thousands of lobotomies were carried out around the globe, but the first discordances started to come out when scientific evidence showed no evident benefit of the surgery and, in some cases, even worsening of symptoms. In parallel, ECT was developed and was considered to be a revolutionary technique indicated for acute episodes of severe depression [12]. However, the broad clinical introduction of antipsychotics and antidepressants in the sixties led to a vast decrease in the use of surgical and electroconvulsive procedures for some decades, until the end of the past century.

In recent years, increased interest in psychiatric disorders and the introduction of worldwide accepted, standardized clinical guidelines have made it possible to perform an accurate diagnosis of the illness. Ethical committees have led to stricter diagnostic criteria and a more scientific approach of epidemiological studies. In recent history, newer techniques have also been developed; in the last decades, the novel interventions such as VNS, TMS, and DBS have been added as treating options for MDD. The surgical techniques have become more precise, safer, and more importantly nonlesional.

\section{Electroconvulsive therapy}

ECT was introduced in the late 1930s and was very rapidly accepted because of its effectiveness in severe psychiatric disorders. After years of animal experiments by Lucio Bini and Ugo Cerletti, the first patient was successfully treated in 1938 with constant alternant current electrical pulses over $200 \mathrm{~V}[12,13,19,28]$. Even though ECT was originally introduced for schizophrenia solely, this technique was widely used for almost all mental illnesses after a short period of time. Subsequently, when the method gained an ample recognition, the indications, contraindications, and search for proper parameters of stimulation were the subjects of investigation. In the 1950s, ECT and other therapeutic options for the time were eclipsed by the arrival of psychiatric pharmacotherapies; nonetheless, it showed its usefulness again many years later, by being effective in pharmacologically resistant patients $[32,82]$.

Nowadays, after grand stigmatization for decades, ECT prevails as one of the most effective therapies in the treatment of severe depressive events; it can reach an effect of up to $80 \%$ [32]. The repetition of this therapy should only be considered in patients who responded well to previous acute sessions [2]. Unfortunately, the benefit is usually not long lasting [36]. This procedure will probably 
remain a viable therapeutic option in medically resistant patients. It should never be considered as a first treatment alternative, which remains pharmacotherapy, due to its costs and temporary documented side effects like confusion and retrograde and/or anterograde amnesia [30].

\section{Vagus nerve stimulation}

VNS was first introduced as an experimental anticonvulsant procedure in dogs by Jacob Zabara in 1985 [123, 124]. A few years later, Kiffin Penry and Dean treated the first human case with VNS in order to treat epilepsy [87]. After several successful studies of epilepsy conducted in numerous centers, the pioneer case with treatment-refractory depression (TRD) as the indication for VNS was presented by Rush et al. at the end of the 1990s [40, 95]. The rationale was based on the beneficial effects on depressive symptoms in patients who had previously received VNS for seizures, but the exact mechanism of action was not known [26, 43, 49]. Long-term studies have proven the good clinical outcome of VNS for MDD while it is well tolerated; a successful response have been described in half of the patients, with complete remission in one third [40, 95, 96, 102]. Even though its mechanism of action is not completely clarified, immunohistological (in animals) and imaging (in TRD patients) studies have endorsed its clinical effect $[81,85]$. It is believed that once the input information from the vagus nerve project into the solitary tract nucleus, it follows an ascending pathway to modulate various structures such as the amygdala, dorsal raphe, locus coeruleus, and the ventromedial prefrontal cortex that produces the effect over mood in patients [85].

Further research is required to elucidate the specific action of VNS, considering the anatomy of the vagus nerve with its projections. Moreover, cost-effectiveness studies are still lacking. Something to keep in mind is that immediately postoperatively and at short-term follow-up, VNS has shown a low effectiveness [76, 102]. However, its beneficial effect at long-term in a substantial amount of patients, together with its low number of unwanted side effects, make this method an attractive treatment for patients suffering from MDD.

\section{Transcranial magnetic stimulation}

TMS is an innovative technique and highly appealing to scientists and patients because of its noninvasive nature. TMS directly modulates superficial areas of the brain. It has been recently developed, and several theories about its mechanism of action have been proposed; induction of neurotransmitter release that alters brain physiology and neuronal depolarization seem to be the most important elements, but more data are required to confirm these statements $[10,11,84]$. In recent times, animal and clinical models have been used trying to understand the antidepressant effects of TMS [33, 34, 52-54, 103]; functional imaging has demonstrated specific changes induced by TMS in brain metabolism, perfusion, and interconnections [23].

High-frequency TMS of the left dorsolateral prefrontal cortex has shown effectiveness in almost one third of pharmacotherapy-resistant MDD patients, always with significant differences compared with sham stimulation [6, 83]. Furthermore, differential opposite effects on depressive behavior have been observed when low versus high frequencies were compared [60, 108]. TMS is a safe procedure with no apparent structural damage after usage for several weeks; some of its advantages are its great tolerance in all patients, the lack of cognitive deterioration, or any other unwanted side effects. However, many questions regarding its mechanism of action have to be answered before expanding its use or indications. Another limitation is the duration of the effect, reflected on a worsening of depressive symptoms only 3 weeks after stimulation. This could represent a serious restraint since continuous stimulation is not possible with TMS.

\section{Lesion procedures}

Ablative surgery to treat mental illnesses is one of the therapies that has expanded more rapidly and widely as a nonpharmacological therapy. Throughout decades, many targets, approaches, and techniques have been tried, with diverse and sometimes contradictory outcomes. Although the effects on mood gained the attention of medical community, due to the growing prevalence and socioeconomic burden, often no objective measurement of the effects was performed, and probably misdiagnosed patients were included into the studies.

\section{Lobotomy/leucotomy}

In 1936, the term psychosurgery was first used in Moniz' prefrontal leucotomy publication in patients with dementia [78]. One year later in 1937, Freeman and Watts introduced a novel approach for the prefrontal leucotomy: the Freeman-Watts standard lobotomy, where a 5-cm-long leucotome was introduced through the roof of the orbit in the direction of the sutura coronalis to perform lesions [37]. Leucotomy by that time was accepted by a great part of the medical community as a treatment for patients with several psychiatric disorders. Publications between 1951 and 1972 showed divergent results: improvement was reported in 
$30 \%$ to $100 \%$ of patients, but frequently defined only as great/much improvement or moderate/slight improvement [14, 27, 57, 58, 75]. Two studies, however, showed no improvement in the number of discharges from a clinic between patients who underwent leucotomy and the control group [74, 94]. In 1961, a report from the UK by Tooth and Newton showed that from a group of more than 10,000 psychiatric patients with affective disorders, schizophrenia, and other disorders, surgery achieved an improvement of approximately $60 \%$. However, there were many side effects reported such as epilepsy, personality changes, urinary incontinence and, especially, a mortality rate of approximately $4 \%$ [114].

\section{Orbital and cortical undercutting}

Scoville described in 1949 the supraorbital cortical undercutting of Brodmann areas 9 and 10, the gyrus cinguli, and the orbital surface, based on previous animal experiments that showed these structures play an important role in emotions. It was believed that with this supraorbital approach, discrete lesions could be performed without disturbing the blood supply of surrounding areas. Scoville's first results showed an improvement in all of his affective psychotic patients. Another study with a small number of patients showed an improvement of approximately $85 \%$ [104, 105]. In 1955, Knight introduced a variation of Scoville's intervention, the restricted orbital undercutting, where he limited the lesion directing his dissection less laterally. Knight based his planning on the circuit of Papez and preferred a restricted resection with the argument that lateral fibers at this level are not of interest for psychiatric disorders; another argument for not going too laterally were the observations that penetrating wounds in the posterolateral lobes resulted in undesirable personality changes. The intervention led to a clear improvement in $69 \%$ of patients with depression and various psychiatric conditions [63]. In both Scoville's intervention and its variant described by Knight, the most important side effects included personality changes, epilepsy, and urine incontinence.

\section{Cingulectomy (cingulotomy)}

The first description of cingulectomy as a treatment of psychiatric disorders is from Le Beau in 1949. The first cingulectomy reports performed in monkeys resulted in unresponsiveness and placidity when Brodmann's cortical area 24 was aspirated via a fine suction. LeBeau found no improvement of the same treatment in five depressive patients with anxiety and pain but good results in three out of four patients with depression and obsessive neurosis [66]. In 1967, Ballantine described the first stereotactic anterior cingulotomy for psychiatric disorders including depression, after the publication of reports by Foltz and White, who by that time had carried out stereotactic cingulotomies in patients with untreatable pain $[9,35]$. The stereotactic neurosurgical technique was applied for the first time in patients by Spiegel and Wycis in 1947. It was a milestone in neurosurgery because specific deep targets could be reached through one burr-hole by using internal cerebral landmarks [109]. Ballantine reported an improvement in $77 \%$ of operated patients with comorbid fear and depression. Other studies showed an improvement between $44 \%$ and $92 \%$ with personality changes, epilepsy, weight gain, and urine incontinence as the most reported side effects $[7,16,93,107]$.

\section{Subcaudate tractotomy}

In 1964, Knight described the stereotactic subcaudate tractotomy using radioactive Yttrium implants in order to perform lesions anteroventral to the head of the caudate nucleus in the substantia innominata (SI). The goal was to interrupt the SI fibers that run from the frontal cortex and amygdala to the hypothalamus. Preclinical studies with monkeys had shown that stimulation of Brodmann area 13, an area just under the SI, caused physical phenomena inducing violent emotions. Therefore, Knight reasoned that a lesion in the SI could influence the intensity of emotional responses. From the initial 15 depressive patients whom he operated on, 14 remained therapy-free after surgery [61]. Other studies showed improvement percentages of 59$100 \%$. The most important reported side effects were fatigue, weight gain, and epilepsy in $1-2 \%$ of the patients $[15,21,41,48,62,70,90,111]$.

\section{Limbic leucotomy}

In 1973, Kelly and Richardson described the stereotactic limbic leucotomy, which consisted of an anterior cingulotomy in combination with a subcaudate tractotomy. Previous studies involving both areas had shown good results when performed separately. Experimental results had already shown a relation between the autonomous responses and emotions at the level of the limbic system. Intraoperative stimulation was applied to patients in order to evoke physiological responses, which would confirm the exact location of the electrode in the target. Of the first 40 operated patients, five of whom with depression, four showed mild to large improvement of depressive symptoms $[55,56]$. Three other studies showed an improvement percentage of $30-78 \%[57,79,97]$. The most common reported side effects were drowsiness, weight gain, and memory problems, but also, epilepsy, urine incontinence, and personality changes were described $[55-57,79,97]$. 
Other procedures

Many other areas and approaches, different from the abovementioned, have been applied for ablative surgery with the intention to cure mental illnesses; however, only poor results or severe complications were obtained. Some of these procedures include topectomy (also called corticectomy), anterior mesoloviotomy, open frontal leucotomy, and in some cases, multiple targets in the same procedure. The general outcome was reported at short-term follow-up or not mentioned; however, three studies report rehabilitation in $50 \%$ of patients or more. Side effects were from moderate to severe, mainly including seizures, personality changes, and postoperative hemorrhage $[65,88,112,115]$.

We summarize some of the most informative and representative outcomes in Table 1.

\section{Deep brain stimulation}

Since its successful application for tremor by Benabid et al. in 1987, DBS is applied on a large scale for movement disorders such as Parkinson's disease, tremor, and dystonia. For each indication, different targets and different theories have been developed with the intention to obtain the best clinical results. In DBS (mostly bilateral), electrodes are implanted in specific brain regions where high-frequency stimulation is applied. Its widely appreciated advantages over lesions are its reversibility and adjustability by manipulating the stimulation parameters. Apart from movement disorders, the applications in the last decade have been extended to psychiatric disorders such as Gilles de la Tourette syndrome and obsessive-compulsive disorder (OCD) $[42,68,106,117]$. In a series of reports performed by Heath et al. between 1979 and 1981, cerebellar stimulation was applied for the treatment of various psychiatric pathologies including intractable depression, schizophrenia, psychiatric conditions secondary to epilepsy, psychotic behavior, and miscellaneous psychiatric symptomatology. Concerning the depressive cases, in five out of six patients, the symptomatology decreased significantly at maximum follow-up without medication. However, evaluation of clinical data is difficult to determine due to lack of standardized scales and absence of other updated reports [22, 44-46]. More recently, DBS to treat MDD has followed diverse approaches in order to alleviate depressive symptoms.

In 2005, Mayberg et al. presented the first clinical study of DBS in depression. The hypothesis to stimulate this area was acquired from observations that showed hyperactivity of the subgenual cingulate cortex (Brodmann area 25; $\mathrm{Cg} 25$ ) in chronic depressed patients. It was thought that this area plays a primary role in processes like learning, memory, motivation, and reward-behaviors that change with depression. In this novel study by Mayberg et al., six patients were implanted and stimulated with parameters adjusted to the apparent optimal benefit. After 6 months, in $67 \%$ of patients, a reduction of more than $50 \%$ on the Hamilton depression rating scale (HDRS) was seen, with a total or partial remission in three patients. Clinically, improvement was referred as an increase in energy, interest, psychomotor speed, and decrease of apathy and anhedonia. In addition, imaging studies showed normalization in the cerebral blood flow of $\mathrm{Cg} 25$ and other areas which appear to be related with depression [73].

After this first study, two case reports concerning DBS for depression in different targets were published. In the first report, Jiménez et al. described considerable improvement after DBS of the inferior thalamic peduncle in a 49-yearold woman with a history of recurrent episodes of major depression for over 20 years. After 24 months follow-up of double-blinded stimulation, the score on the HDRS decreased significantly. After a 2-month double-blinded OFF stimulation period, there was an evident worsening of symptomatology with an increase on depressive scales, suggesting that the positive effect was obtained by DBS and not due to a placebo effect [51]. In the second report, Kosel et al. described the case of a 62-year-old woman with treatment refractory MDD with comorbid neuroleptic-induced tardive dyskinesias. DBS of the globus pallidus internus induced an evident drop in the HDRS score after stimulation [64]. Schlaepfer et al. published the positive results of DBS of the nucleus accumbens for depression in three patients, with an immediate effect on depressive ratings. Double-blinded periods with stimulation $\mathrm{ON}$ and OFF demonstrated a beneficial outcome only when ON stimulation was applied. Moreover, the positive behavioral changes in these patients were supported by positron emission tomography imaging that correlated symptomatology with an augmentation of metabolism in the nucleus accumbens, amygdala, and dorsolateral and dorsomedial prefrontal cortex, and reduced metabolism in the ventral and ventrolateral medial prefrontal cortex [101]. On the other hand, Aouizerate et al. implanted electrodes in two patients with a history of MDD and OCD. After clinical evaluations, they concluded that the best target for DBS to alleviate OCD symptoms was the ventral caudate, and for the best outcome in depression, the nucleus accumbens was pointed as the best option [3]. In a recent study, Sartorius et al. reported on the case of a 64-year-old woman with history of TRD for over four decades treated with DBS in the lateral habenula. After electrode implantation, the patient presented two relapses, one attributable to initial adjustment of parameters and the second probably due to a traumatism. When the proper functioning of the stimulator was demonstrated, complete remission was achieved for several weeks. After 60 weeks of DBS, the 


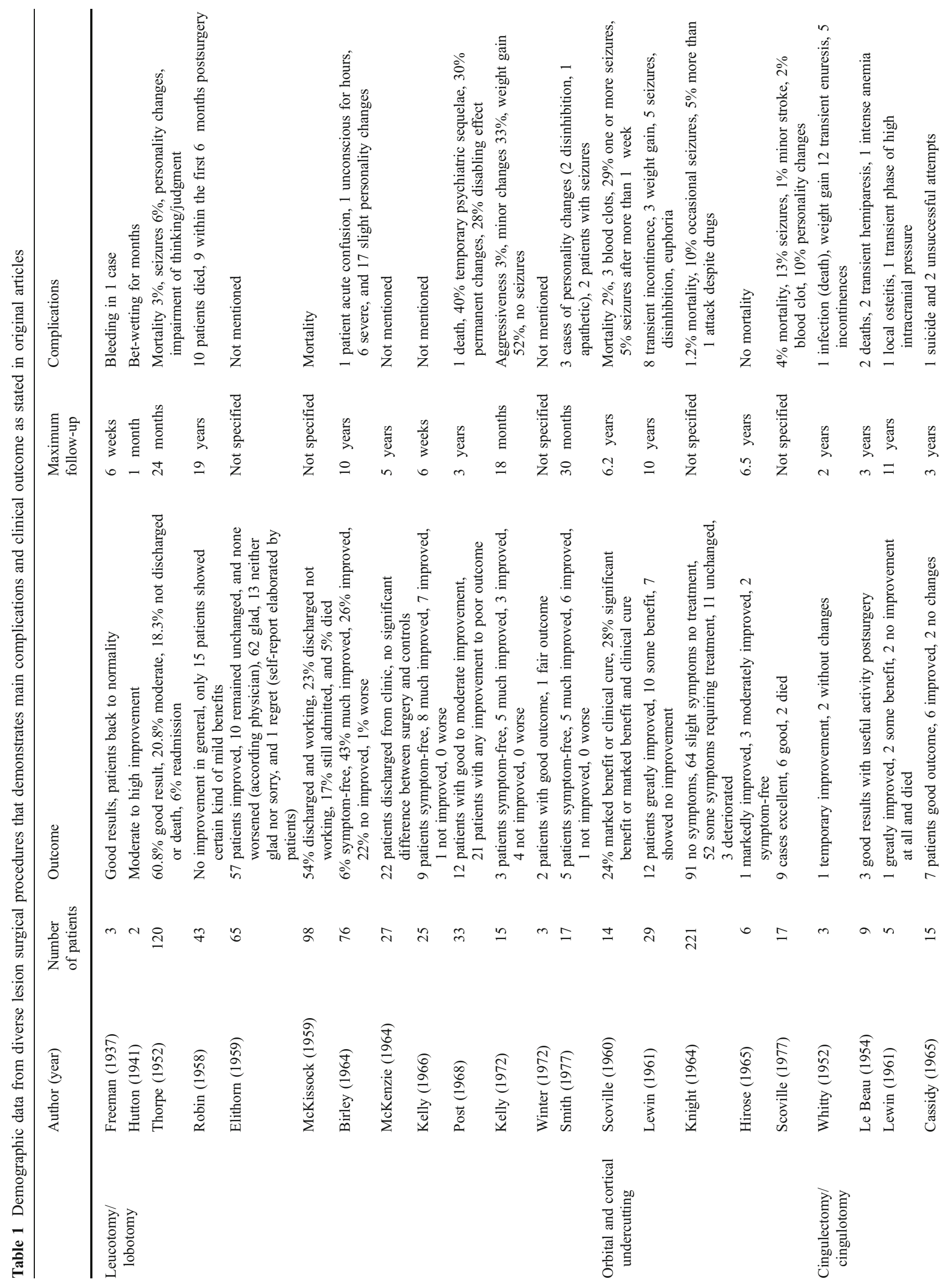






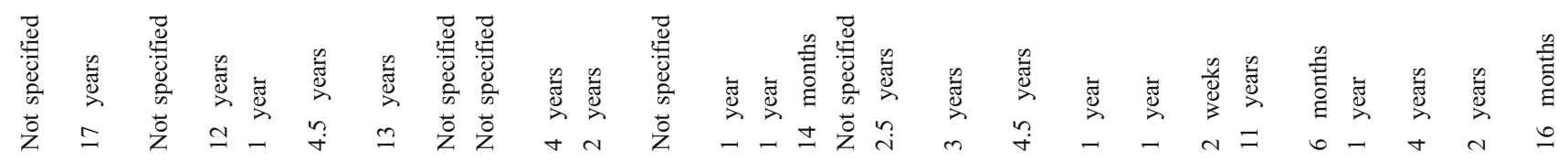

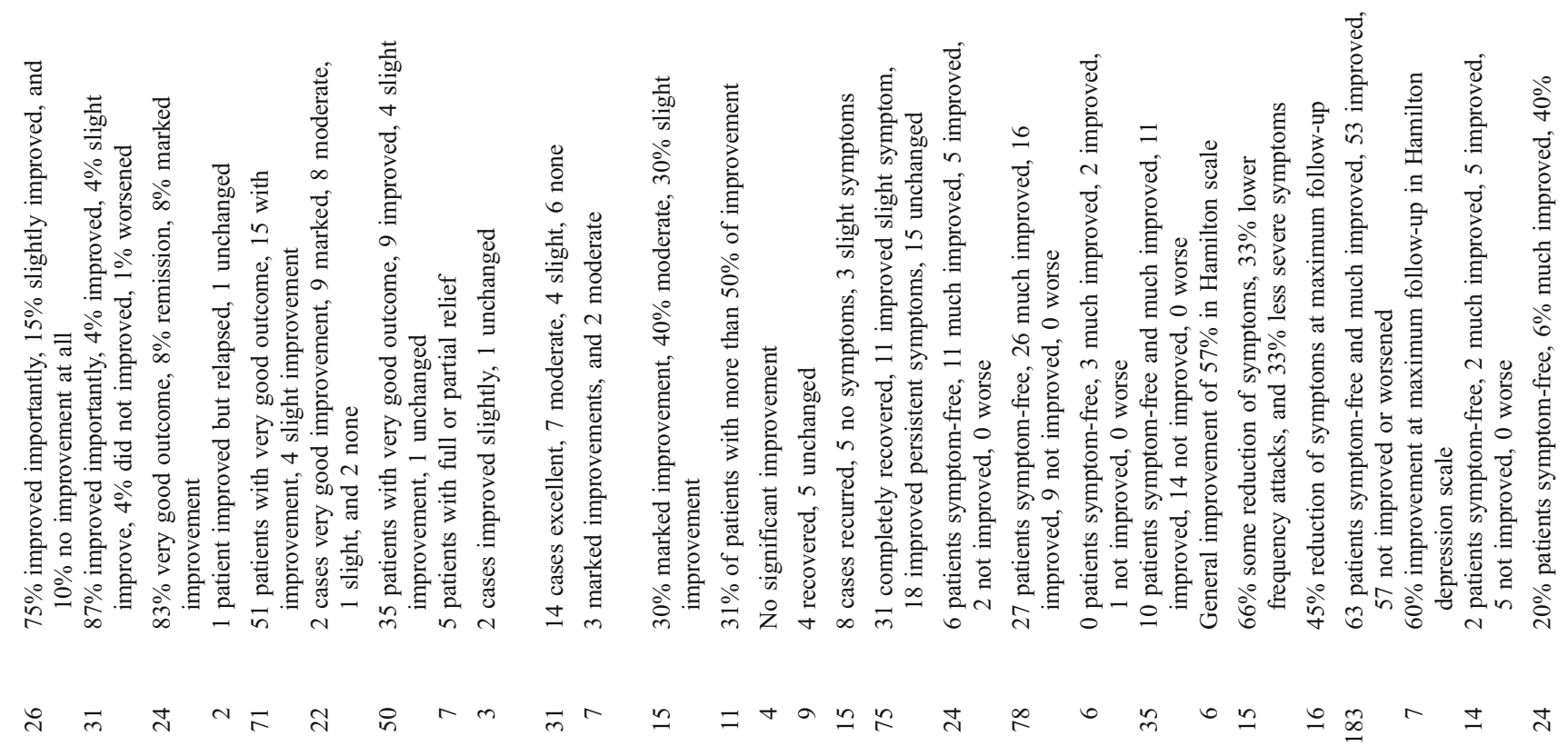

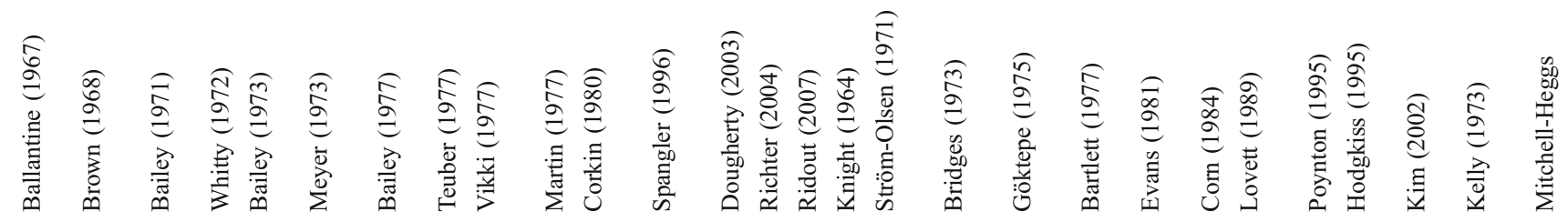




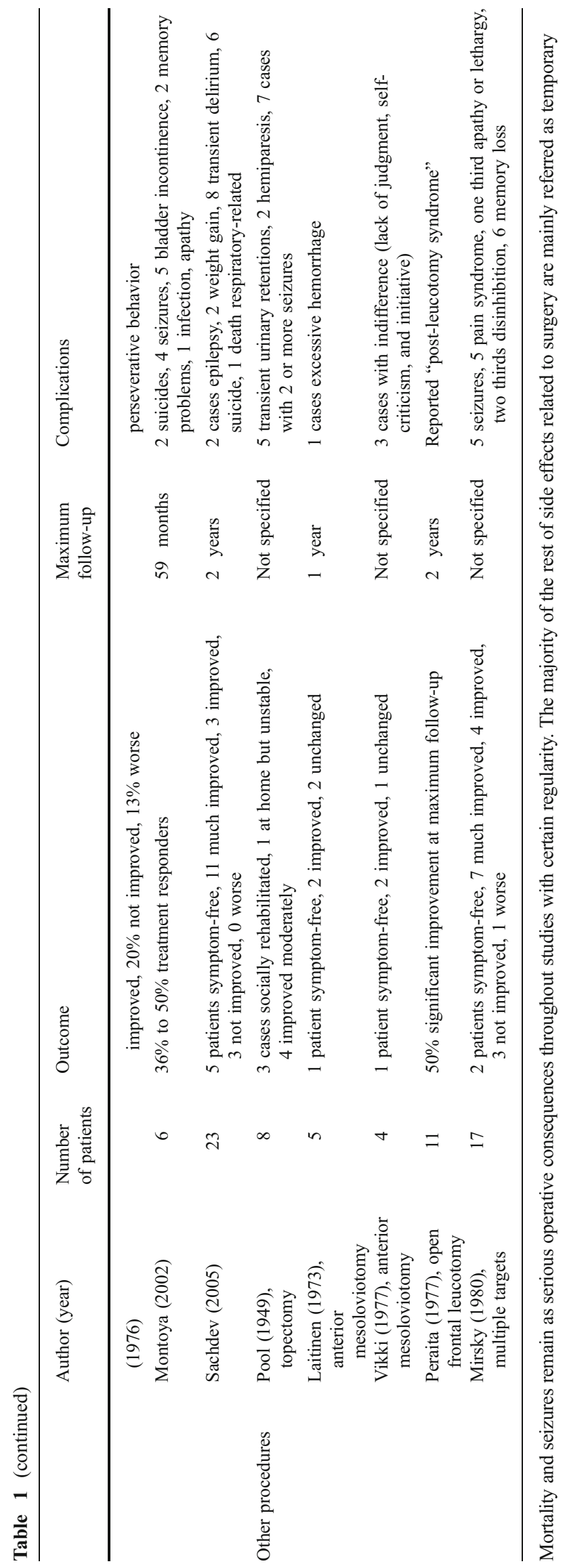

patient remained with an HDRS score of 0 without reported complications or side effects [100].

Nowadays, six main DBS targets of interest remain that have been reported (Table 2). Neuromodulation could be one of the most efficient techniques for this disorder due to the fluctuant behavior of patients and the high co-morbidity that accompanies this condition. Analysis of DBS results of the mentioned targets shows promising responses and evident positive outcomes with minimal side effects. Nevertheless, cost-benefit analysis and good selection of patients are indispensable matters for a successful result.

\section{Discussion}

In this review, we have summarized the reports of nonpharmacological therapies for the treatment of MDD, ablative surgery being the first method essayed at the end of the nineteenth century. Even though it was abandoned shortly after its initiation, it was retaken on the 1930s in a systematic manner and applied at various centers with diverse techniques for several decades. Nowadays, these procedures have been abandoned due to the low results with a high complication rate, together with the development of minimally invasive surgery. ECT merged years after psychosurgery as an attractive option at that time to treat many psychiatric conditions without surgical intervention, and showing special aid for severe mood crises, the latter being one of the most important indications even today, with over $80 \%$ of improvement if correct inclusion criteria are used. ECT remains a valid intervention even in our days, but with specific indications due to their limitations. Short-lasting effects of this therapy seem to be the most important disadvantage to take into account before its application $[32,116]$. At the beginning of the twentieth century, the first case of VNS to treat depression was reported. This therapy has shown since then in various reports, positive outcomes, and good rates of remission for MDD. However, very little about its mechanism of action has been elucidated, and further research is needed to endorse it. During this same time, for over one decade, TMS has been introduced into the psychiatric field, and its therapeutic effect over depression has been examined. Nevertheless, stimulation guidelines and interactions with medications should be better established to avoid relapse of symptoms. Recently, in 2005, the first report of DBS for MDD draws the attention to this well-established method used to treat other conditions for over 20 years. This procedure has demonstrated during this time high rates of remission, low number of side effects, and very few complications related to the surgery.

Several authors have published different outcomes for all of these methods since the first half of the twentieth 
century. However, in the beginning of the past century, the deficiency of standardized disease criteria, absence of consensus in MDD and TRD definitions, lack of diagnostic instruments, poor follow-up clinimetric evaluations, and high rates of mortality led in many cases to misuse or abuse of these techniques. The poor description of therapy outcomes, complications, and side effects of reports performed in the past complicates an objective evaluation of data in our days. These premises together could have possibly biased the results obtained formerly. The quality of evidence reported in many articles made it very difficult to interpret the results and hardened the data analysis.

On the other hand, the novel developments available nowadays are more ethically justified with better scientific bases, minimally invasive techniques, and more objective evaluation instruments. Innovative procedures as VNS, TMS, and DBS allow physicians to reproduce maximal clinical effects for sustained periods of time that could be adapted to each patient's needs and to combine them with pharmacotherapy [71]. Neuromodulation offers the possibility to adapt parameters to avoid undesired consequences and to obtain the maximum clinical benefit. TMS possesses the advantage over any other therapy by being the least invasive procedure, but still with an unspecific target of action and outcome. ECT is the first line option for acute events in depressive crises. VNS, although proven to be an effective treatment, is not yet a well-established method for MDD. Although in all these therapies the results are promising, their mechanisms of action should be better clarified [84]. Algorithms should be developed to extend these treatments in the most convenient phase of the disorder, allowing also better combination with conventional therapies.

When considering the more invasive treatment options at the present time DBS seems to offer more advantages, fewer complications, and fewer side effects compared with lesions. Moreover, DBS has known more years of careful testing compared with other stimulation methods, its application being supported by larger scientific evidence. Nowadays, lesions should not be considered anymore except if no other alternative is available due to the above-mentioned complications, low rates of success, and irreversibility.

Depression is one of the disorders with the largest comorbidity rate, not only related to other psychiatric conditions but also in association with other illnesses such as Alzheimer and Parkinson disease among others [4, 20, 25, 51, 99]. This premise is another pending aspect that should be kept in mind if real progress is intended for the treatment patients suffering from MDD; in the same way, anxiety-related symptoms should often also be evaluated in order to measure treatment effectiveness. 


\section{Future perspective}

Novel stimulatory techniques are being developed using minimal invasive techniques. In this respect, DBS seems to be one of the most promising procedures due to its reversibility. DBS also offers the possibility to control the therapeutic effect by simply switching off the stimulation, which is usually not easily possible in other treatments. The main problem of DBS in MDD is at the moment the diversity of potential targets, varying from the cortex to the habenula. One way of solving this problem is to elucidate the mechanism of action of DBS in MDD by using computational and animal models.

Open Access This article is distributed under the terms of the Creative Commons Attribution Noncommercial License which permits any noncommercial use, distribution, and reproduction in any medium, provided the original author(s) and source are credited.

\section{References}

1. American Psychiatric Association (2000) Diagnostic and statistical manual of mental disorders (DSM-IV-TR). American Psychiatric Association, Arlington

2. Andrade C, Nelson AI, Fink M (2003) ECT in the management of major depression: implications of recent research. World $\mathrm{J}$ Biol Psychiatry 4(3):139-140

3. Aouizerate B, Cuny E, Bardinet E, Yelnik J, Martin-Guehl C, Rotge JY, Rougier A, Bioulac B, Tignol J, Mallet L, Burbaud P, Guehl D (2009) Distinct striatal targets in treating obsessive-compulsive disorder and major depression. J Neurosurg 111(4):775-779

4. Aouizerate B, Cuny E, Martin-Guehl C, Guehl D, Amieva H, Benazzouz A, Fabrigoule C, Allard M, Rougier A, Bioulac B, Tignol J, Burbaud P (2004) Deep brain stimulation of the ventral caudate nucleus in the treatment of obsessivecompulsive disorder and major depression. Case report. J Neurosurg 101(4):682-686

5. Aouizerate B, Martin-Guehl C, Cuny E, Guehl D, Amieva H, Benazzouz A, Fabrigoule C, Allard M, Rougier A, Burbaud P, Tignol J, Bioulac B (2005) Deep brain stimulation of the ventral striatum in the treatment of obsessive-compulsive disorder and major depresión. Med Sci (Paris) 21(10):811-813

6. Avery DH, Holtzheimer PE 3rd, Fawaz W, Russo J, Neumaier J, Dunner DL, Haynor DR, Claypoole KH, Wajdik C, Roy-Byrne P (2006) A controlled study of repetitive transcranial magnetic stimulation in medication-resistant major depression. Biol Psychiatry 59(2):187-194

7. Bailey HR, Dowling JL, Davies E (1973) Studies in depression. 3. The control of affective illness by cingulotractotomy: a review of 150 cases. Med J Aust 2(8):366-371

8. Bailey HR, Dowling JL, Swanton CH, Davies E (1971) Studies in depression. 1. Cingulo-tractotomy in the treatment of severe affective illness. Med J Aust 1(1):8-12

9. Ballantine HT Jr, Cassidy WL, Flanagan NB, Marino R Jr (1967) Stereotaxic anterior cingulotomy for neuropsychiatric illness and intractable pain. J Neurosurg 26(5):488-495

10. Ben-Shachar D, Belmaker RH, Grisaru N, Klein E (1997) Transcranial magnetic stimulation induces alterations in brain monoamines. J Neural Transm 104:191-197
11. Ben-Shachar D, Gazawi H, Riboyad-Levin J, Klein E (1999) Chronic repetitive transcranial magnetic stimulation alters betaadrenergic and 5-HT2 receptor characteristics in rat brain. Brain Res 816:78-83

12. Bini L (1938) Experimental researches on epileptic attacks induced by the electric current. The treatment of schizophrenia: insulin, shock, cardiozol, sleep treatment. Am J Psychiatry 94 (Suppl):172-174

13. Bini L (1995) Professor Bini's notes on the first electro-shock. Convuls Ther 11(4):260-261

14. Birley JL (1964) Modified frontal leucotomy: a review of 106 cases. Br J Psychiatry 110:211-221

15. Bridges PK, Goktepe EO, Maratos J (1973) A comparative review of patients with obsessional neurosis and with depression treated by psychosurgery. Br J Psychiatry 123(577):663674

16. Brown MH, Lighthill JA (1968) Selective anterior cingulotomy: a psychosurgical evaluation. J Neurosurg 29:513-519

17. Burton LA, Labar D (1999) Emotional status after right vs. left temporal lobectomy. Seizure 8(2):116-119

18. Cassidy WL, Ballantine HT Jr, Flanagan NB (1965) Frontal cingulotomy for affective disorders. Recent Adv Biol Psychiatry 8:269-282

19. Cerletti U (1950) Old and new information about electroshock. Am J Psychiatry 107(2):87-94

20. Chaudhuri KR, Schapira AH (2009) Non-motor symptoms of Parkinson's disease: dopaminergic pathophysiology and treatment. Lancet Neurol 8(5):464-474

21. Corn TH, Hornig A, Thompson C, Bridges PK, Bartlett JR, Checkley SA (1984) A neuroendocrine study of stereotactic subcaudate tractotomy. Br J Psychiatry 144:417-420

22. Correa AJ, Llewellyn RC, Epps J, Jarrott D, Eiswirth C, Heath RG (1980) Chronic cerebellar stimulation in the modulation of behavior. Acta Neurol Latinoam 26(3):143-153

23. Dell'Osso B, Mundo E, D'Urso N, Pozzoli S, Buoli M, Ciabatti M, Rosanova M, Massimini M, Bellina V, Mariotti M, Altamura AC (2009) Augmentative repetitive navigated transcranial magnetic stimulation (rTMS) in drug-resistant bipolar depression. Bipolar Disord 11(1):76-81

24. Dougherty DD, Weiss AP, Cosgrove GR, Alpert NM, Cassem EH, Nierenberg AA, Price BH, Mayberg HS, Fischman AJ, Rauch SL (2003) Cerebral metabolic correlates as potential predictors of response to anterior cingulotomy for treatment of major depression. J Neurosurg 99(6):1010-1017

25. Ehrt U, Larsen JP, Aarsland D (2009) Pain and its relationship to depression in Parkinson disease. Am J Geriatr Psychiatry 17 (4):269-275

26. Elger G, Hoppe C, Falkai P, Rush AJ, Elger CE (2000) Vagus nerve stimulation is associated with mood improvements in epilepsy patients. Epilepsy Res 42(2-3):203-210

27. Elithorn A (1959) Discussion on psychosurgery; prefrontal leucotomy and depression. Proc R Soc Med 52(3):203-206

28. Endler NS (1988) The origins of electroconvulsive therapy (ECT). Convuls Ther 4(1):5-23

29. Evans BM, Bridges PK, Bartlett JR (1981) Electroencephalographic changes as prognostic indicators after psychosurgery. $\mathrm{J}$ Neurol Neurosurg Psychiatry 44(5):444-447

30. Falconer DW, Cleland J, Fielding S, Reid IC (2009) Using the Cambridge Neuropsychological Test Automated Battery (CAN$\mathrm{TAB}$ ) to assess the cognitive impact of electroconvulsive therapy on visual and visuospatial memory. Psychol Med. doi:10.1017/ S0033291709991243

31. Fava M (2003) Diagnosis and definition of treatment-resistant depression. Biol Psychiatry 15(8):649-659

32. Fink M (2001) Convulsive therapy: a review of the first 55 years. J Affect Disord 63(1-3):1-15 
33. Fleischmann A, Prolov K, Abarbanel J, Belmaker RH (1995) The effect of transcranial magnetic stimulation of rat brain on behavioral models of depression. Brain Res 699(1):130 132

34. Fleischmann A, Sternheim A, Etgen AM, Li C, Grisaru N, Belmaker RH (1996) Transcranial magnetic stimulation downregulates beta-adrenoreceptors in rat cortex. J Neural Transm 103 (11):1361-1366

35. Foltz EL, White LE Jr (1962) Pain "relief" by frontal cingulumotomy. J Neurosurg 19:89-100

36. Frederikse M, Petrides G, Kellner C (2006) Continuation and maintenance electroconvulsive therapy for the treatment of depressive illness: a response to the National Institute for Clinical Excellence report. J ECT 1:13-17

37. Freeman W, Watts JW (1937) Prefrontal lobotomy in the treatment of mental disorders. South Med J 30(1):23-31

38. Freeman W, Watts JW (1948) Prefrontal lobotomy; indications and contraindications. Arch Neurol Psychiatry 60(1):97-100

39. Fulton JF, Jacobsen CF (1935) Fonctions des lobes frontaux; etude comparee chez l'homme et les singes chimpanzes. In proceedings of the International Neurological Congress, London

40. George MS, Sackeim HA, Rush AJ, Marangell LB, Nahas Z, Husain MM, Lisanby S, Burt T, Goldman J, Ballenger JC (2000) Vagus nerve stimulation: a new tool for brain research and therapy. Biol Psychiatry 47(4):287-295

41. Goktepe EO, Young LB, Bridges PK (1975) A further review of the results of stereotactic subcaudate tractotomy. Br J Psychiatry 126:270-280

42. Greenberg BD, Malone DA, Friehs GM, Rezai AR, Kubu CS, Malloy PF, Salloway SP, Okun MS, Goodman WK, Rasmussen SA (2006) Three-year outcomes in deep brain stimulation for highly resistant obsessive-compulsive disorder. Neuropsychopharmacology 31(11):2384-2393

43. Harden CL, Pulver MC, Ravdin LD, Nikolov B, Halper JP, Labar DR (2000) A Pilot study of mood in epilepsy patients treated with vagus nerve stimulation. Epilepsy Behav 1(2):9399

44. Heath RG, Llewellyn RC, Rouchell AM (1979) Brain mechanisms in psychiatric illness: rationale for and results of treatment with cerebellar stimulation. In: Hitchcock ER, Ballantine HT, Meyerson BA (eds) Modern concepts in psychiatric surgery. Elsevier/North-Holland Biomedical Press, Amsterdam

45. Heath RG, Llewellyn RC, Rouchell AM (1980) The cerebellar pacemaker for intractable behavioral disorders and epilepsy: follow-up report. Biol Psychiatry 15(2):243-256

46. Heath RG, Rouchell AM, Llewellyn RC, Walker CF (1981) Cerebellar pacemaker patients: an update. Biol Psychiatry 16 (10):953-962

47. Hirose S (1965) Orbito-ventromedial undercutting 1957-1963; follow-up study of 77 cases. Am J Psychiatry 121:1194-1202

48. Hodgkiss AD, Malizia AL, Bartlett JR, Bridges PK (1995) Outcome after the psychosurgical operation of stereotactic subcaudate tractotomy, 1979-1991. J Neuropsychiatry Clin Neurosci 7(2):230-234

49. Hoppe C, Helmstaedter C, Scherrmann J, Elger CE (2001) Selfreported mood changes following 6 months of vagus nerve stimulation in epilepsy patients. Epilepsy Behav 2(4):335-342

50. Hutton EL, Fleming GWTH, Fox FE (1941) Early results of prefrontal leucotomy. Lancet 238(6149):3-7

51. Jiménez F, Velasco F, Salin-Pascual R, Hernández JA, Velasco M, Criales JL, Nicolini H (2005) A patient with a resistant major depression disorder treated with deep brain stimulation in the inferior thalamic peduncle. Neurosurgery 57(3):585-593

52. Keck ME, Engelmann M, Müller MB, Henniger MS, Hermann B, Rupprecht R, Neumann ID, Toschi N, Landgraf R, Post A (2000) Repetitive transcranial magnetic stimulation induces active coping strategies and attenuates the neuroendocrine stress response in rats. J Psychiatr Res 34(4-5):265-276

53. Keck ME, Sillaber I, Ebner K, Welt T, Toschi N, Kaehler ST, Singewald N, Philippu A, Elbel GK, Wotjak CT, Holsboer F, Landgraf R, Engelmann M (2000) Acute transcranial magnetic stimulation of frontal brain regions selectively modulates the release of vasopressin, biogenic amines and amino acids in the rat brain. Eur J NeuroSci 12(10):3713-3720

54. Keck ME, Welt T, Müller MB, Erhardt A, Ohl F, Toschi N, Holsboer F, Sillaber I (2002) Repetitive transcranial magnetic stimulation increases the release of dopamine in the mesolimbic and mesostriatal system. Neuropharmacology 43 (1):101-109

55. Kelly D, Richardson A, Mitchell-Heggs N (1973) Stereotactic limbic leucotomy: neurophysiological aspects and operative technique. Br J Psychiatry 123(573):133-140

56. Kelly D, Richardson A, Mitchell-Heggs N, Greenup J, Chen C, Hafner RJ (1973) Stereotactic limbic leucotomy: a preliminary report on forty patients. Br J Psychiatry 123(573):141-148

57. Kelly DH, Walter CJ, Mitchell-Hegss N, Sargant W (1972) Modified leucotomy assessed clinically, physiologically and psychologically at six weeks and eighteen months. $\mathrm{Br} \mathrm{J}$ Psychiatry 120(554):19-29

58. Kelly DH, Walter CJ, Sargant W (1966) Modified leucotomy assessed by forearm blood flow and other measurements. Br J Psychiatry 112(490):871-881

59. Kim MC, Lee TK, Choi CR (2002) Review of long-term results of stereotactic psychosurgery. Neurol Med Chir (Tokyo) 42 (9):365-371

60. Kimbrell TA, Little JT, Dunn RT, Frye MA, Greenberg BD, Wassermann EM, Repella JD, Danielson AL, Willis MW, Benson BE, Speer AM, Osuch E, George MS, Post RM (1999) Frequency dependence of antidepressant response to left prefrontal repetitive transcranial magnetic stimulation (rTMS) as a function of baseline cerebral glucose metabolism. Biol Psychiatry 46(12):1603-1613

61. Knight G (1964) The orbital cortex as an objective in the surgical treatment of mental illness. The results of 450 cases of open operation and the development of the stereotactic approach. Br J Surg 51:114-124

62. Knight G (1965) Stereotactic tractotomy in the surgical treatment of mental illness. J Neurol Neurosurg Psychiatry 28:304-310

63. Knight GC, Tredgold RF (1955) Orbital leucotomy; a review of 52 cases. Lancet 268(6872):981-986

64. Kosel M, Sturm V, Frick C, Lenartz D, Zeidler G, Brodesser D, Schlaepfer TE (2007) Mood improvement after deep brain stimulation of the internal globus pallidus for tardive dyskinesia in a patient suffering from major depression. J Psychiatr Res 41 (9):801-803

65. Laitinen LV, Livingston KE (1973) Surgical approaches in psychiatry. Medical and technical publishing co. limited, Lancaster

66. Le Beau J (1954) Anterior cingulectomy in man. J Neurosurg 11 (3):268-276

67. Lewin W (1961) observations on selective leucotomy. J Neurol Neurosurg Psychiatry 24:37-44

68. Lipsman N, Neimat JS, Lozano AM (2007) Deep brain stimulation for treatment-refractory obsessive-compulsive disorder: the search for a valid target. Neurosurgery 61(1):1-11

69. Little A (2009) Treatment-resistant depression. Am Fam Physician 80(2):167-172

70. Lovett LM, Crimmins R, Shaw DM (1989) Outcome in unipolar affective disorder after stereotactic tractotomy. Br J Psychiatry 155:547-550

71. Lozano AM, Mayberg HS, Giacobbe P, Hamani C, Craddock RC, Kennedy SH (2008) Subcallosal cingulate gyrus deep brain 
stimulation for treatment-resistant depression. Biol Psychiatry 64 (6):461-467

72. Malone DA Jr, Dougherty DD, Rezai AR, Carpenter LL, Friehs GM, Eskandar EN, Rauch SL, Rasmussen SA, Machado AG, Kubu CS, Tyrka AR, Price LH, Stypulkowski PH, Giftakis JE, Rise MT, Malloy PF, Salloway SP, Greenberg BD (2009) Deep brain stimulation of the ventral capsule/ventral striatum for treatment-resistant depression. Biol Psychiatry 65(4):267-275

73. Mayberg HS, Lozano AM, Voon V, McNeely HE, Seminowicz D, Hamani C, Schwalb JM, Kennedy SH (2005) Deep brain stimulation for treatment-resistant depression. Neuron 45 (5):651-660

74. McKenzie KG, Kaczanowski G (1964) Prefrontal leukotomy: a five-year controlled study. Can Med Assoc J 91:1193-1196

75. McKissock W (1959) Discussion on psychosurgery. Proc R Soc Med 52(3):206-209

76. Milby AH, Halpern $\mathrm{CH}$, Baltuch GH (2008) Vagus nerve stimulation for epilepsy and depression. Neurotherapeutics $5(1): 75-85$

77. Mitchell-Heggs N, Kelly D, Richardson A (1976) Stereotactic limbic leucotomy - a follow-up at 16 months. Br J Psychiatry 128:226-240

78. Moniz E (1937) Prefrontal leucotomy in the treatment of mental disorders. Amer J Psychiatry 93:1379-1385

79. Montoya A, Weiss AP, Price BH, Cassem EH, Dougherty DD, Nierenberg AA, Rauch SL, Cosgrove GR (2002) Magnetic resonance imaging-guided stereotactic limbic leukotomy for treatment of intractable psychiatric disease. Neurosurgery 50 (5): 1043-1049

80. Neimat JS, Hamani C, Giacobbe P, Merskey H, Kennedy SH, Mayberg HS, Lozano AM (2008) Neural stimulation successfully treats depression in patients with prior ablative cingulotomy. Am J Psychiatry 165(6):687-693

81. Nemeroff CB, Mayberg HS, Krahl SE, McNamara J, Frazer A, Henry TR, George MS, Charney DS, Brannan SK (2006) VNS therapy in treatment-resistant depression: clinical evidence and putative neurobiological mechanisms. Neuropsychopharmacology 31(7):1345-1355

82. Oral ET, Tomruk N, Plesnicar BK, Hotujac L, Kocmur M, Koychev G, Sartorius N (2008) Electroconvulsive therapy in psychiatric practice: a selective review of the evidence. Neuro Endocrinol Lett 29(Suppl 1):11-32

83. O'Reardon JP, Solvason HB, Janicak PG, Sampson S, Isenberg KE, Nahas Z, McDonald WM, Avery D, Fitzgerald PB, Loo C, Demitrack MA, George MS, Sackeim HA (2007) Efficacy and safety of transcranial magnetic stimulation in the acute treatment of major depresión: a multisite randomized controlled trial. Biol Psychiatry 62(11):1208-1216

84. Padberg F, George MS (2009) Repetitive transcranial magnetic stimulation of the prefrontal cortex in depression. Exp Neurol 219(1):2-13

85. Pardo JV, Sheikh SA, Schwindt GC, Lee JT, Kuskowski MA, Surerus C, Lewis SM, Abuzzahab FS, Adson DE, Rittberg BR (2008) Chronic vagus nerve stimulation for treatment-resistant depression decreases resting ventromedial prefrontal glucose metabolism. Neuroimage 42(2):879-889

86. Parker G, Brotchie H (2009) Do the old psychostimulant drugs have a role in managing treatment-resistant depression? Acta Psychiatr Scand. doi:10.1111/j.1600-0447.2009.01434.x

87. Penry JK, Dean JC (1990) Prevention of intractable partial seizures by intermittent vagal stimulation in humans: preliminary results. Epilepsia 31(Suppl 2):S40-S43

88. Pool JL (1949) Topectomy, the treatment of mental illness by frontal gyrectomy or bilateral subtotal ablation of frontal cortex. Lancet 2(18):776-781
89. Post F, Rees WL, Schurr PH (1968) An evaluation of bimedial leucotomy. Br J Psychiatry 114(515):1223-1246

90. Poynton AM, Kartsounis LD, Bridges PK (1995) A prospective clinical study of stereotactic subcaudate tractotomy. Psychol Med 25(4):763-770

91. Ressler KJ, Mayberg HS (2007) Targeting abnormal neural circuits in mood and anxiety disorders: from the laboratory to the clinic. Nat Neurosci 10(9):1116-1124

92. Richter EO, Davis KD, Hamani C, Hutchison WD, Dostrovsky JO, Lozano AM (2004) Cingulotomy for psychiatric disease: microelectrode guidance, a callosal reference system for documenting lesion location, and clinical results. Neurosurgery 54 (3):622-628

93. Ridout N, O'Carroll RE, Dritschel B, Christmas D, Eljamel M, Matthews K (2007) Emotion recognition from dynamic emotional displays following anterior cingulotomy and anterior capsulotomy for chronic depression. Neuropsychologia 45 (8): $1735-1743$

94. Robin AA (1958) A controlled study of the effects of leucotomy. J Neurol Neurosurg Psychiatry 21(4):262-269

95. Rush AJ, George MS, Sackeim HA, Marangell LB, Husain MM, Giller C, Nahas Z, Haines S, Simpson RK Jr, Goodman R (2000) Vagus nerve stimulation (VNS) for treatment-resistant depressions: a multicenter study. Biol Psychiatry 47(4):276286

96. Rush AJ, Sackeim HA, Marangell LB, George MS, Brannan SK, Davis SM, Lavori P, Howland R, Kling MA, Rittberg B, Carpenter L, Ninan P, Moreno F, Schwartz T, Conway C, Burke M, Barry JJ (2005) Effects of 12 months of vagus nerve stimulation in treatment-resistant depression: a naturalistic study. Biol Psychiatry 58(5):355-363

97. Sachdev PS, Sachdev J (2005) Long-term outcome of neurosurgery for the treatment of resistant depression. J Neuropsychiatry Clin Neurosci 17(4):478-485

98. Sadock BJ, Sadock VA (2005) Synopsis of psychiatry. Lippincott Williams \& Wilkins, Philadelphia

99. Santangelo G, Vitale C, Trojano L, Longo K, Cozzolino A, Grossi D, Barone P (2009) Relationship between depression and cognitive dysfunctions in Parkinson's disease without dementia. J Neurol 256(4):632-638

100. Sartorius A, Kiening KL, Kirsch P, Gall CC, Haberkorn U, Unterberg AW, Henn FA, Meyer-Lindenberg A (2010) Remission of major depression under deep brain stimulation of the lateral habenula in a therapy-refractory patient. Biol Psychiatry 67(2):e9-e11

101. Schlaepfer TE, Cohen MX, Frick C, Kosel M, Brodesser D, Axmacher N, Joe AY, Kreft M, Lenartz D, Sturm V (2008) Deep brain stimulation to reward circuitry alleviates anhedonia in refractory major depression. Neuropsychopharmacology 33 (2):368-377

102. Schlaepfer TE, Frick C, Zobel A, Maier W, Heuser I, Bajbouj M, O'Keane V, Corcoran C, Adolfsson R, Trimble M, Rau H, Hoff HJ, Padberg F, Müller-Siecheneder F, Audenaert K, Van den Abbeele D, Stanga Z, Hasdemir M (2008) Vagus nerve stimulation for depression: efficacy and safety in a European study. Psychol Med 38(5):651-661

103. Schutter DJ, van Honk J (2010) An endocrine perspective on the role of steroid hormones in the antidepressant treatment efficacy of transcranial magnetic stimulation. Psychoneuroendocrinology 35(1):171-178

104. Scoville WB (1949) Selective cortical undercutting as a means of modifying and studying frontal lobe function in man; preliminary report of 43 operative cases. J Neurosurg 6(1):65-73

105. Scoville WB (1960) Late results of orbital undercutting. Report of 76 patients undergoing quantitative selective lobotomies. Am J Psychiatry 117:525-532 
106. Servello D, Porta M, Sassi M, Brambilla A, Robertson MM (2007) Deep brain stimulation in 18 patients with severe Gilles de la Tourette syndrome refractory to treatment: the surgery and stimulation. J Neurol Neurosurg Psychiatry 79(2):136-142

107. Spangler WJ, Cosgrove GR, Ballantine HT Jr, Cassem EH, Rauch SL, Nierenberg A et al (1996) Magnetic resonance imageguided stereotactic cingulotomy for intractable psychiatric disease. Neurosurgery 38(6):1071-1076

108. Speer AM, Benson BE, Kimbrell TK, Wassermann EM, Willis MW, Herscovitch P, Post RM (2009) Opposite effects of high and low frequency rTMS on mood in depressed patients: relationship to baseline cerebral activity on PET. J Affect Disord 115(3):386-394

109. Spiegel EA, Wycis HT, Marks M, Lee AJ (1947) Stereotaxic apparatus for operations on the human brain. Science 106 (2754):349-350

110. Stone JL (2001) Dr. Gottlieb Burckhardt-the pioneer of psychosurgery. J Hist Neurosci 10(1):79-92

111. Strom-Olsen R, Carlisle S (1971) Bi-frontal stereotactic tractotomy. A follow-up study of its effects on 210 patients. Br J Psychiatry 118(543):141-154

112. Sweet WH, Obrador S, Martin-Rodriguez JG (1977) Neurosurgical treatment in psychiatry, pain and epilepsy. University Park Press, Baltimore

113. Thorpe FT, Hardman J (1952) The lower quadrant leucotomy. J Ment Sci 98(412):389-400

114. Tooth JC, Newton MP (1961) Leucotomy in England and Wales 1942-1954. Reports on public health and medical subjects. Report No.: 104. Her Majesty's Stationery Office, London
115. Valenstein ES (1980) The psychosurgery debate-scientific, legal, and ethical perspectives. W.H. Freeman and Company, San Francisco

116. Valentí M, Benabarre A, García-Amador M, Molina O, Bernardo M, Vieta E (2008) Electroconvulsive therapy in the treatment of mixed states in bipolar disorder. Eur Psychiatr 23 (1):53-56

117. Visser-Vandewalle V, Temel Y, Boon P, Vreeling F, Colle H, Hoogland G, Groenewegen HJ, van der Linden C (2003) Chronic bilateral thalamic stimulation: a new therapeutic approach in intractable Tourette syndrome. Report of three cases. J Neurosurg 99(6):1094-1100

118. Watts JW, Freeman W (1948) Prefrontal lobotomy; complications and their treatment. J Int Coll Surg 11(4):343-350

119. Whitty CWM (1972) Effects of anterior cingulectomy in man. Proc R Soc Med 65:463-469

120. Whitty CW, Duffield JE, Tov' PM, Cairns H (1952) Anterior cingulectomy in the treatment of mental disease. Lancet 1 (6706):475-481

121. Winter A (1972) Depression and intractable pain treated by modified prefrontal lobotomy. J Med Soc N J 69(9):757759

122. World Health Organization (2001) The World Health Report 2001. New Understanding, New Hope, Mental Health

123. Zabara J (1985) Peripheral control of hypersyncrhonus discharge in epilepsy. Electroencephalogr Clin Neurophysiol 61(3):S162

124. Zabara J (1992) Inhibition of experimental seizures in canines by repetitive vagal stimulation. Epilepsia 33(6):1005-1012 